\title{
SIRM-SIC appropriateness criteria for the use of Cardiac Computed Tomography. Part 1: Congenital heart diseases, primary prevention, risk assessment before surgery, suspected CAD in symptomatic patients, plaque and epicardial adipose tissue characterization, and functional assessment of stenosis
}

\author{
Antonio Esposito ${ }^{1,2}$ - Marco Francone ${ }^{3,4}$. Daniele Andreini ${ }^{5,6}$. Vitaliano Buffa ${ }^{7}$. Filippo Cademartiri ${ }^{8}$. \\ lacopo Carbone ${ }^{9}$. Alberto Clemente ${ }^{10}$. Andrea Igoren Guaricci ${ }^{11}$. Marco Guglielmo ${ }^{5}$. Ciro Indolfi ${ }^{12}$. \\ Ludovico La Grutta $^{13}$. Guido Ligabue ${ }^{14,15}$. Carlo Liguori ${ }^{16}$. Giuseppe Mercuro ${ }^{17}$. Saima Mushtaq ${ }^{5}$ Danilo Neglia ${ }^{18}$. \\ Anna Palmisano ${ }^{1,2} \cdot$ Roberto Sciagrà $^{19} \cdot$ Sara Seitun $^{20} \cdot$ Davide Vignale $^{1,2} \cdot$ Gianluca Pontone $^{5} \cdot$ Nazario Carrabba ${ }^{21}$
}

Received: 5 April 2021 / Accepted: 20 May 2021 / Published online: 23 June 2021

(c) The Author(s) 2021

\begin{abstract}
In the past 20 years, Cardiac Computed Tomography (CCT) has become a pivotal technique for the noninvasive diagnostic work-up of coronary and cardiac diseases. Continuous technical and methodological improvements, combined with fast growing scientific evidence, have progressively expanded the clinical role of CCT. Recent large multicenter randomized clinical trials documented the high prognostic value of CCT and its capability to increase the cost-effectiveness of the management of patients with suspected CAD. In the meantime, CCT, initially perceived as a simple non-invasive technique for studying coronary anatomy, has transformed into a multiparametric "one-stop-shop" approach able to investigate the heart in a comprehensive way, including functional, structural and pathophysiological biomarkers. In this complex and revolutionary scenario, it is urgently needed to provide an updated guide for the appropriate use of CCT in different clinical settings. This manuscript, endorsed by the Italian Society of Medical and Interventional Radiology (SIRM) and by the Italian Society of Cardiology (SIC), represents the first of two consensus documents collecting the expert opinion of Radiologists and Cardiologists about current appropriate use of CCT.
\end{abstract}

Keywords Coronary CT angiography $\cdot$ Chest pain $\cdot$ Congenital heart disease $\cdot$ Epicardial adipose tissue $\cdot$ Plaque $\cdot$ Stenosis

\section{Introduction}

Cardiac Computed Tomography (CCT) was historically adopted as a tool to rule-out coronary artery disease (CAD) due to the well-established very high negative predictive value. Recently, the results of multicenter randomized clinical trials have changed the perception of CCT in the clinical world, leading the scientific community to recognize CCT as the first line diagnostic test for most of the patients with suspected chronic coronary syndrome [1] and in some cases of acute chest pain presentation [2]. Moreover, due to technical

Antonio Esposito

esposito.antonio@hsr.it

Extended author information available on the last page of the article improvements and scientific progress, CCT was promoted as a potential test to implement prevention strategies in some specific settings [3], and as an imaging tool able to characterize coronary plaques [4], myocardium [5] and epicardial fat [6]. Furthermore, different strategies were developed to integrate the outstanding anatomical data with functional information revealing the pathophysiological impact of a coronary stenosis [7] (Fig. 1).

In this complex and revolutionary scenario, in which guidelines help the translation of evidences into clinical practice [8], there is a clear need of updating the previously published documents on appropriateness for clinical/practical use of CCT [9-12].

This manuscript, endorsed by the Italian Society of Medical and Interventional Radiology (SIRM) and by the Italian Society of Cardiology (SIC), represents the first of two 
consensus documents collecting the expert opinion of Radiologists and Cardiologists about current appropriate use of CCT and integrates the guidelines for appropriate use of cardiovascular magnetic resonance (CMR) recently published by the same working group [13].

\section{Definition of appropriateness and applied methodology}

The writing committee discussed the table of content and assigned referrals for each chapter.

Each referral conducted literature review and drafted the assigned section highlighting indications and rating them according to the following score:

A. Strong recommendation: there is evidence, general agreement, or both, that the test is useful (benefit $>>>$ risk).

B. Moderate recommendation: there is conflicting evidence or opinion about the usefulness of the test; the weight of evidence/opinion, however, is strongly in favor of the test's usefulness. (benefit $>>$ risk).

C. Weak recommendation: the test's usefulness is less well established; there is a small net benefit (benefit $\geq$ risk)

D. No recommendation: there is evidence or general agreement that the risk/harm outweighs benefits (benefit $=$ or $<$ risk).
E. Expert opinion: there is insufficient evidence or evidence is unclear or conflicting, but this is what the working group recommends. Further research is recommended in this area.

Assigned scores were discussed in consensus by all authors and unanimously approved.

\section{Congenital heart diseases}

In pre- and post-surgical complex congenital heart diseases (CHD), multimodality imaging is required for both the detailed evaluation of cardiovascular anatomy and for the functional characterization of cardiac chambers and flows. Catheterization is required for pulmonary vascular resistances calculation, whereas for most types of CHD and congenital coronary artery anomalies (CAAs) CCT is adopted as a complementary imaging modality [14] (Table 1).

Echocardiography is the initial imaging tool for morphofunctional evaluation; however, a frequently limited acoustic window hampers the assessment of the mediastinal vessels, extra-cardiac surgical conduits, and intra-cardiac complex anatomy, particularly in adults with grown-up congenital heart diseases (GUCH).

The use of CCT has been described in patients of all ages and with CHD of all levels of complexity, especially when echocardiography is not exhaustive. CCT is generally recommended in complex conditions that require investigation of
Fig. 1 Graphical overview of the main applications of Cardiac Computed Tomography discussed in this part I appropriateness criteria guidelines from SIRM-SIC

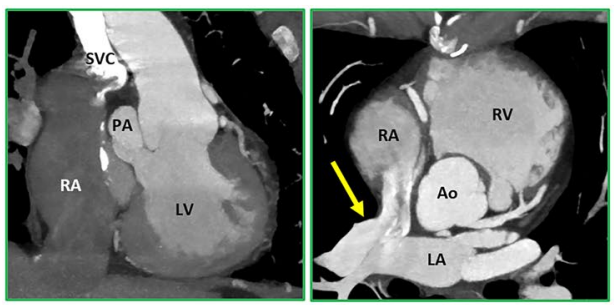

Congenital heart diseases

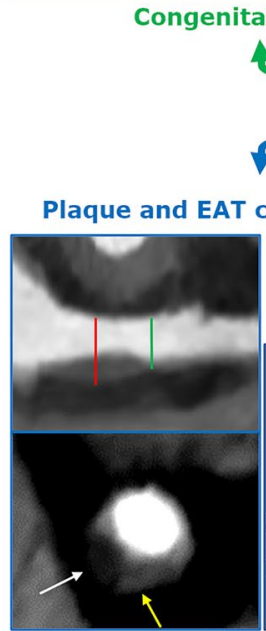

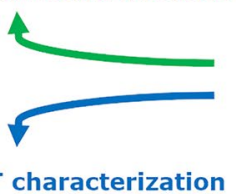

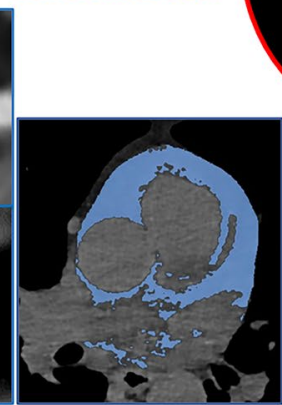

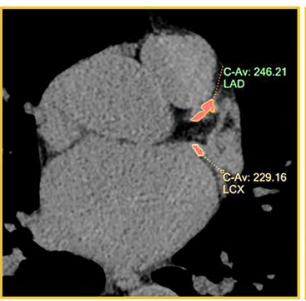

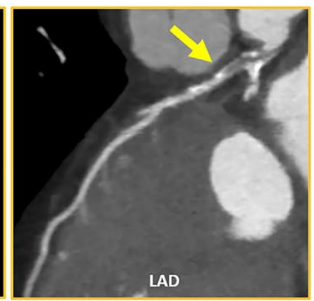

CACS and CCTA
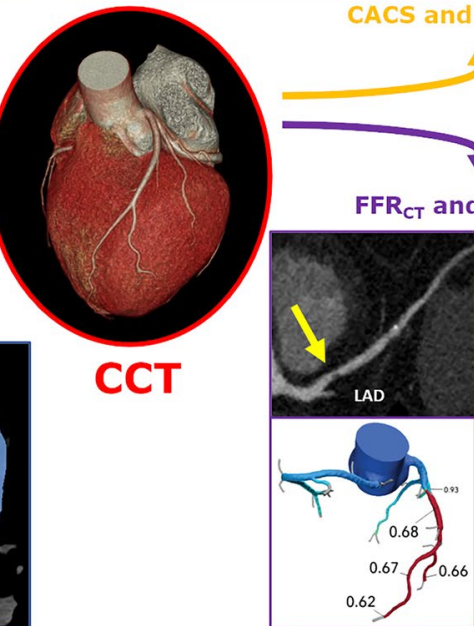
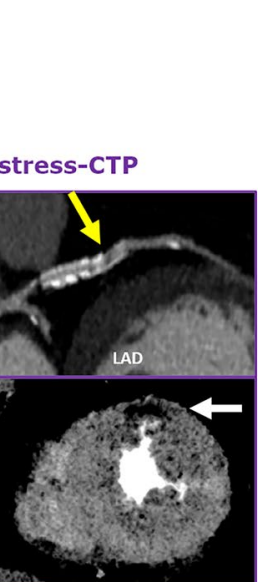
Table 1 Congenital heart diseases

\begin{tabular}{lll}
\hline Clinical setting & Diagnostic step & $\begin{array}{l}\text { Recommenda- Indication } \\
\text { tion }\end{array}$
\end{tabular}

\section{Coronary arteries anomalies}

Isolated congenital coronary artery anomaly First diagnosis

Follow-up

A

\section{Conotruncal CHD}

Tetralogy of Fallot (TOF)

D-loop transposition of the great arteries

Truncus arteriosus

\section{Septal anomalies}

Atrial septal defects (ASD) and partial anomalous pulmonary venous return (PAPVR)

Ventricular septal defects (VSD) and atrioventricular septal defects (AVSD)

\section{Mediastinal vessels anomalies}

Aortic coarctation and aortic arch anomalies

Total anomalous pulmonary venous return

Vascular rings and pulmonary artery slings

\section{Single-ventricle heart disease}

Functional single ventricle

After stage 1 palliation (e.g., systemic-topulmonary artery shunt, patent ductus arteriosus stent)
First diagnosis

A

Follow-up (postoperative)

First diagnosis

Follow-up (postoperative) C

Follow-up (unrepaired)

First diagnosis

D

Follow-up (postoperative)

First diagnosis

Follow-up

A

First diagnosis

A

Follow-up (postoperative) B

First diagnosis

A

Follow-up (postoperative) B

First diagnosis

A

Surgical planning and follow-up
Identification of coronary artery origin, course, angulation from the aortic root, ostial atresia, presence and length of intramural course, presence of arteriovenous fistula

Worsening clinical status or new signs/symptoms Surveillance in patients with no or mild sequelae

Not recommended

Presence of associated major aortopulmonary collateral arteries (MAPCAs)

Depiction of coronary arteries anatomy before pulmonary valve replacement

In symptomatic patients or as surveillance in patients with no or mild sequelae especially when CMR is contraindicated

\section{Not recommended}

Evaluation of reimplanted coronary artery in asymptomatic and symptomatic patients

Surveillance in patients with neoaortic root dilation

In symptomatic patients or as surveillance in patients with no or mild sequelae especially when CMR is contraindicated

Evaluation prior to surgery

Surveillance in symptomatic patients or in asymptomatic patients with moderate or severe truncal stenosis or regurgitation

In patients with sinus venous defect and PAPVR for procedural planning

In symptomatic patients or as surveillance in patients with no or mild sequelae

Surveillance in asymptomatic patients with moderate or severe ASD and PAPVR of $>1$ pulmonary vein

Not recommended

Not recommended

Evaluation prior to surgery

Surveillance in patients with mild aortic coarctation Surveillance in asymptomatic patients after surgery

Evaluation and preprocedural planning

Surveillance in patients with no or mild sequelae

Vascular and tracheobronchial anatomy depiction and preprocedural planning

Surveillance in patients with no or mild sequelae

Evaluation prior to stage 1 palliation

Evaluation prior to stage 2 and stage 3 palliation Surveillance in patients with no or mild sequelae 
coronary vessels or complex vascular and thoracic anatomy $[15,16]$. CCT provides high anatomical detail about pulmonary vessels, when compared to surgical findings [17], and about aorto-pulmonary collaterals prior to surgery in patients with pulmonary atresia, septal defects, and major aorto-pulmonary collateral arteries.

In patients with suspected vascular rings and slings or tracheobronchial narrowing for complete cartilaginous rings, CCT is the method of choice for the pre-surgical evaluation of tracheobronchial tree and pulmonary parenchyma [16]. Congenital coronary anomalies are relatively common in patients with Tetralogy of Fallot, and the definition of origin and course prior to surgery is needful, particularly in patients with an anomalous coronary that crosses the right ventricle outflow tract [18].

CMR remains the method of choice in the follow-up of complex CHD due to the absence of ionizing radiation and for its capability to quantify vessel flows and ventricular function and to identify myocardial fibrosis. However, CMR is time consuming and image quality may be reduced in patients with metallic devices. CCT provides better visualization of stents, conduits, and metallic objects and is safe in patients with implanted pacemakers and defibrillators [19]. Moreover, $\mathrm{CCT}$ can measure bi-ventricular volumes and function with very high accuracy when scanners with adequate temporal resolution are adopted. Therefore, CCT plays an important role in the follow-up of adult patients with GUCHs who cannot undergo CMR [20].

Finally, CCT may provide useful morphological information to avoid external coronary artery compression related to device release in transcatheter pulmonary valve replacement [21] and to identify sub-sternal course of coronary arteries before repeated sternotomy [22].

The main limitation of CCT is ionizing radiation exposure; however, low-dose acquisition protocols can be adopted [23].

\section{Primary prevention in asymptomatic patients}

\section{Coronary artery calcium scoring}

Coronary Artery Calcium Score (CACS), reported as Agatston score [24], measures the amount of calcium in the coronary arteries and is a surrogate marker for atherosclerotic burden. CACS predicts the risk of events in asymptomatic individuals independently of the presence of obstructive CAD [25]. A proportional relationship between stratified CACS $(0,1-99,100-399$ and $\geq 400)$, total atherosclerotic plaque burden [26], and outcome has been found [27] (Table 2).

Recent studies [28, 29] have shown the additional value of CACS beyond traditional risk factors, supporting the integration of CACS into cardiovascular risk assessment. The 2016 European Society of Cardiology (ESC) guidelines for cardiovascular disease prevention gave a class II recommendation for CACS in intermediate-risk patients [30]. The 2019 ESC guidelines for chronic coronary syndromes gave CACS a IIb recommendation for screening asymptomatic patients [1], with particular value as a risk modifier in patients with intermediate $(5-15 \%)$ pre-test probability (PTP) [1].

CACS may have a role also in individuals aged 45-to75 years with low cardiovascular risk but with strong family history of premature CAD and in diabetics patients aged $>40$ years or at intermediate-risk of early $\operatorname{CAD}[31,32]$.

The absence of CACS carries a favorable 5-year and 15 -year prognosis for patients with and without diabetes, respectively [33].

Finally, CACS is considered useful for guiding preventive medical therapy [34], avoiding misclassifications and under- or over-treatment [35]. As a result, according to AHA and ACC guidelines for the management of blood cholesterol, CACS assessment is considered crucial to decide if starting statin therapy [36].

\section{Coronary CT angiography}

According to 2019 ESC guidelines on chronic coronary syndromes, coronary CT Angiography (CCTA) is not recommended for extensive screening of asymptomatic individuals [1]. However, CCTA has an incremental prognostic value over the Framingham risk score for prediction of mortality and non-fatal myocardial infarction in asymptomatic individuals with CACS from 101 to 400 [37]. Moreover, it may be reasonable to consider CCTA in selected subgroups of asymptomatic patients at high risk of coronary events, such as diabetic patients. In this setting, CCTA identifies patients at increased risk of cardiac events with incremental value over clinical risk assessment and CACS [38]. However, RCT and meta-analysis showed that CCTA does not significantly reduce major adverse cardiovascular events (MACEs) [39] or the rate of non-fatal myocardial infarction and hospitalization for heart failure [40], even if it significantly reduces the rate of any cardiac event [40]. Furthermore, in high risk patients, CCTA promotes a more aggressive modification of risk factors and medical or revascularization therapy [41]. 
Table 2 Primary prevention in asymptomatic patients-Coronary Artery Calcium Score (CACS) and coronary CT angiography (CCTA)

\begin{tabular}{|c|c|c|c|}
\hline Clinical setting & Diagnostic step & $\begin{array}{l}\text { Recom- } \\
\text { menda- } \\
\text { tion }\end{array}$ & Indications \\
\hline CACS in patients with low risk of CAD & First diagnosis & $\mathrm{B}$ & $\begin{array}{l}\text { In } 40 \text {-to- } 75 \text { years old patients with strong family history of prema- } \\
\text { ture CAD }\end{array}$ \\
\hline CACS in patients with intermediate risk of CAD & First diagnosis & A & $\begin{array}{l}\text { In } 40 \text {-to- } 75 \text { years old patients } \\
\text { If } C A C S=0 \text {, no statin or aspirin required unless persistent smoker } \\
\text { or strong family history of CAD }\end{array}$ \\
\hline CACS in patients with high risk of CAD & First diagnosis & $\mathrm{D}$ & Not recommended \\
\hline CACS in patients with diabetes & First diagnosis & $\mathrm{B}$ & In $>40$ years old patients \\
\hline Repeated CACS & Follow-up & $\mathrm{B}$ & $\begin{array}{l}\text { At } 5 \text { years in patients with CACS }=0 \\
\text { At } 3 \text {-to- } 5 \text { years in patients with CACS }>0 \text { or diabetes }\end{array}$ \\
\hline CCTA after CACS for CAD screening & First diagnosis & $\mathrm{B}$ & In patients with CACS in the range $101-400$ \\
\hline \multirow[t]{3}{*}{ CCTA for CAD screening } & First diagnosis & $\mathrm{D}$ & Extensive screening is not recommended \\
\hline & & $\mathrm{B}$ & $\begin{array}{l}\text { Screening in high-risk populations (e.g., patients with diabetes, } \\
\text { patients with familial hypercholesterolaemia) } \\
\text { Screening in specific populations (e.g., pre-participation screening } \\
\text { of athletes }>35 \text { years old, specific jobs such as in aviation) }\end{array}$ \\
\hline & Follow-up & A & Follow-up of heart transplantation \\
\hline
\end{tabular}

This is reflected in 2019 ESC guidelines that suggest that asymptomatic diabetic subjects with CACS $>400$ may be referred for functional imaging or CCTA [32]. However, inherent limitations of CCTA in patients with heavily calcified coronary arteries [42] and local technological level and operator expertise should be taken into account.

Finally, some evidence suggests that CCTA could enhance screening in asymptomatic individuals in specific sporting (i.e., pre-participation screening of athletes aged $>35$ years or in young athletes for the exclusion of significant CAD or coronary anomalies) [43, 44] or working (i.e., aviation personnel) [45] settings (Table 2).

\section{Risk assessment before major surgery}

\section{Non-cardiac major surgery}

Non-cardiac surgery is associated with an incidence of complications from 7 to $11 \%$, with a mortality rate of $0.8 \%$ to $1.5 \%$, largely driven ( $42 \%$ of cases) by cardiac complications. Based on the rate of cardiovascular events (death or myocardial infarction within 30 days from surgery), surgical procedures are classified at low, intermediate, or high risk ( $<1 \%, 1-5 \%$, and $>5 \%$, respectively). The current guidelines recommend coronary functional testing for patients with an unknown or impaired functional status undergoing intermediate-to-high risk non-cardiac planned surgery [46, 47]. Nevertheless, the capability to predict MACEs within 30 days from non-cardiac surgery remains limited [48].
In a recently published meta-analysis, CCTA was found to safely predict freedom from perioperative MACEs in a cohort of patients at high risk according to clinical indices [49]. The severity and extent of CAD improved risk stratification, and multivessel disease was associated with the highest risk (OR 8.9). Similarly, increasing CACS was associated with higher risk of perioperative MACEs (CACS $\geq 100$, OR 5.1; CACS $\geq 1000$, OR 10.4) [49]. Given its well-know very high NPV, CCTA is recommended in patients with low-tointermediate risk of CAD undergoing high risk surgery, particularly if unable to take functional stress testing or with inconclusive findings. Nevertheless, further trials are needed to better identify the subclasses of patients getting the higher value from a functional or anatomical approach in this specific setting (Table 3 ).

\section{Cardiac surgery}

CAD needs to be screened in patients scheduled for cardiac surgery for pre-operative risk assessment. In particular, a thorough cardiological evaluation is indicated in patients with severe valve disease with history of CAD, suspected ischemia, systolic dysfunction, male with age $>40$ years, post-menopausal women, and patients with one or more risk factors. Several studies indicated that CCTA can reliably replace invasive coronary angiography (ICA) as a screening tool before valve interventions [50-52], especially in patients at low-to-intermediate risk of CAD, and in patients at high risk of ICA-related complications (i.e., aortic dissection, valve vegetations, prosthetic thrombosis) (Table 3). 


\section{Suspected CAD in symptomatic patients}

In the recent past, stable symptomatic patients with chest pain were non-invasively assessed using different functional tests, including mainly treadmill testing, stress echocardiography and single photon emission computed tomography (SPECT). Stress perfusion cardiac magnetic resonance (stress-CMR) and positron emission tomography (PET) were less used due to availability and costs concerns, albeit showing a higher diagnostic accuracy. Unfortunately, despite routine use of these tests, only one-third of the patients with a positive functional test turns out to be affected by obstructive CAD at ICA [53], revealing a high rate of false-positive or undetermined results of these non-invasive functional tests (Table 4).

In the recent years, CCTA was found to detect with high accuracy non-obstructive CAD defined by ICA, and to reduce unnecessary ICAs when compared to functional testing [54].

The prognostic value of CCTA in stable symptomatic patients is no longer debated since the publication of the results of the PROMISE [54] and the SCOT-HEART [55] trials. CCTA is highly effective as a guide to enhance risk factors modification and preventive therapy adoption [56]. CCTA was found to reduce the rate of events when performed in addition to routine test $[55,56]$, to provide outcome information comparable to functional imaging [57], and, when associated with non-invasive fractional flow reserve $\left(\mathrm{FFR}_{\mathrm{CT}}\right)$, it is comparable to ICA with invasive FFR in targeted revascularization [58].

In line with these evidence, the latest update of the National Institute for Health and Care Excellence (NICE) clinical guidelines [59] and the 2019 ESC guidelines for the diagnosis and management of chronic coronary syndromes [1] recommended CCTA as the initial test to rule-out CAD in patients in which obstructive CAD cannot be excluded by clinical assessment alone (Class I). CCTA should be also considered as an alternative to ICA for non-diagnostic or indeterminate results of other noninvasive tests (Class IIa).

For stenosis estimated to be in the range $50-90 \%$ at CCTA, functional significance should be considered uncertain [60] [61], being inducible ischemia found in approximately $50 \%$ of patients with obstructive CAD at CCTA ( $\geq 50 \%$ ); hence, myocardial ischemia test is recommended as in the case of non-diagnostic CCTA (Class I) [1].

In past studies adopting old technology, it was found that the accuracy of CCTA was influenced by the pre-test probability (PTP) of CAD [62], being particularly high for patients with low-to-intermediate PTP of CAD [63, 64] driven by the very high NPV of CCTA [65-68]. Recent technological advancement, with improvement of spatial and temporal resolution, has led to a significant improvement also of the PPV and of the specificity [69-72]. These findings, associated with the tendency of clinical risk scores to overestimate the pre-test probability of obstructive CAD [1, 73, 74], led to consider CCTA irrespective of PTP, with the exception of patients with very high PTP (>90\%) in whom ICA is indicated, and for patients with very low clinical likelihood $(\leq 5 \%)$, in whom no further test is indicated (ESC 2019).

However, CCTA is to be avoided in the presence of conditions which cannot ensure good image quality related to local availability and expertise, scanner technology, and patient characteristics, including extensive coronary calcification, irregular heart rate, severe obesity, and inability to breath-hold (Class III) [1].

\section{Coronary atherosclerotic plaque and epicardial adipose tissue characterization}

CCTA has the unique capability to non-invasively quantify coronary atherosclerosis and to characterize plaque morphology and composition with high accuracy compared to histology and intravascular ultrasound (IVUS) [75]. This is important for risk stratification and has the potential

Table 3 CCTA-based risk assessment before major non-cardiac and cardiac surgery

\begin{tabular}{|c|c|c|c|}
\hline \multicolumn{4}{|l|}{ Major surgery } \\
\hline Clinical setting & Diagnostic step & $\begin{array}{l}\text { Recommenda- } \\
\text { tion }\end{array}$ & Indications \\
\hline Low-to-intermediate surgical risk & First diagnosis & $\mathrm{D}$ & Not recommended \\
\hline \multirow[t]{3}{*}{ High surgical risk } & First diagnosis & $\mathrm{B}$ & In low risk of CAD \\
\hline & & A & Intermediate risk of CAD \\
\hline & & $\mathrm{E}$ & In high risk of CAD \\
\hline Cardiac valvular surgery & First diagnosis & A & $\begin{array}{l}\text { Patients with suspected ischemia, systolic disfunction, } \\
\text { male }>40 \text { years, post-menopausal women, patients } \\
\text { with } \geq 1 \text { risk factors }\end{array}$ \\
\hline
\end{tabular}


Table 4 CCTA in symptomatic patients with suspected CAD

\begin{tabular}{|c|c|c|c|}
\hline Clinical setting & Diagnostic step & $\begin{array}{l}\text { Recom- } \\
\text { menda- } \\
\text { tion }\end{array}$ & Indication \\
\hline Patients with conditions that likely hamper image quality & First diagnosis & $\mathrm{C}$ & $\begin{array}{l}\text { The imaging modality with higher cost-effectiveness } \\
\text { should be identified case by case for difficult patients } \\
\text { because conditions that likely hamper image quality in } \\
\text { CT (e.g., high-grade obesity, limited compliance) may } \\
\text { also hamper feasibility of different functional imaging } \\
\text { modalities } \\
\text { Extensive coronary calcifications or highly irregular } \\
\text { heartbeat should suggest considering other imaging } \\
\text { modalities }\end{array}$ \\
\hline $\begin{array}{l}\text { Patients with low-to-intermediate pre-test likelihood of } \\
\text { CAD }\end{array}$ & First diagnosis & A & As first line test \\
\hline Patients with high pre-test likelihood of CAD & First diagnosis & $\mathrm{B}$ & As first line test \\
\hline Patients with very high pre-test likelihood of CAD & First diagnosis & $\mathrm{D}$ & Not recommended \\
\hline Patients with low pre-test likelihood of CAD & First diagnosis & $\begin{array}{l}\mathrm{A} \\
\mathrm{C}\end{array}$ & $\begin{array}{l}\text { After positive appropriate functional stress test } \\
\text { After negative appropriate functional stress test }\end{array}$ \\
\hline Patients with high pre-test likelihood of CAD & First diagnosis & $\begin{array}{l}\mathrm{C} \\
\mathrm{A}\end{array}$ & $\begin{array}{l}\text { After positive appropriate functional stress test } \\
\text { After negative appropriate functional stress test }\end{array}$ \\
\hline Regardless of pre-test likelihood of CAD & First diagnosis & A & $\begin{array}{l}\text { After equivocal or uninterpretable appropriate functional } \\
\text { stress test } \\
\text { After two or more appropriate functional stress test with } \\
\text { opposite results }\end{array}$ \\
\hline Patients with suspected vasospastic angina & First diagnosis & A & To determine the extent of underlying CAD \\
\hline
\end{tabular}

advantage to guide preventive therapy [56] and to assess treatment efficacy [76] (Table 5).

Patients with obstructive CAD have worse outcomes compared to patients with nonobstructive or absent CAD [77]. However, most of acute coronary syndromes arise from nonobstructive plaques with vulnerable features [78]. CCTA can identify high-risk plaques (HRP) by evaluating several features such as the napkin ring sign (thin overlying fibrous cap), positive vessel remodeling (ratio between lesion diameter and reference diameter $>1.1$ ), low attenuation ( $<30 \mathrm{HU}$ ), and spotty calcifications (focal calcification within the coronary artery wall $<3 \mathrm{~mm}$ in maximum diameter). Recent trials [55, 79-81] highlighted that evaluation of non-obstructive HRPs has incremental prognostic value in predicting coronary events [82] beyond cardiovascular risk factors and obstructive CAD presence [79, 81].

Other plaque characteristics, such as extent and location (proximal vs distal), have been associated with clinical outcome [81, 83], and percent atheroma volume and stenosis diameter have been found as independent predictors for the development of obstructive CAD [84]. Furthermore, it has been shown that, after an acute coronary syndrome, predictors of future events are large plaque burden and lipid-rich lesions, which can be assessed by CCTA. For this purpose, comprehensive CT-based scores (such as the CT-Leaman
Table 5 Coronary Atherosclerotic Plaque and Epicardial Adipose Tissue (EAT) characterization

\begin{tabular}{|c|c|c|c|}
\hline Clinical setting & Diagnostic step & $\begin{array}{l}\text { Recom- } \\
\text { menda- } \\
\text { tion }\end{array}$ & Indication \\
\hline \multirow[t]{2}{*}{ Plaque imaging } & First diagnosis & B & $\begin{array}{l}\text { Classification of plaques as soft, calcified, or mixed } \\
\text { Identification and description of high-risk plaque features }\end{array}$ \\
\hline & Follow-up & $\mathrm{C}$ & $\begin{array}{l}\text { Classification of plaques as soft, calcified, or mixed } \\
\text { Identification and description of high-risk plaque features }\end{array}$ \\
\hline \multirow[t]{2}{*}{$\begin{array}{l}\text { Epicardial } \\
\text { adipose tissue } \\
\text { (EAT) }\end{array}$} & First diagnosis & $\mathrm{E}$ & $\begin{array}{l}\text { Measuring of EAT volume and attenuation is not cur- } \\
\text { rently clinically indicated. Interesting tool needing } \\
\text { further research }\end{array}$ \\
\hline & Follow-up & $\mathrm{E}$ & $\begin{array}{l}\text { Measuring of EAT volume and attenuation is not cur- } \\
\text { rently clinically indicated. Interesting tool needing } \\
\text { further research }\end{array}$ \\
\hline
\end{tabular}


score) have been created and proved to be associated with future cardiovascular events [85].

These data support the reporting of HRP features presence (if more than 2 HRP features are evident) even for nonobstructive lesions, as suggested by CAD-RADS guidelines [86].

Some technical limitations may impact on CCTA-based plaque characterization, most importantly spatial resolution and other factors such as a certain degree of density overlap in lipid-rich and fibrous-rich non-calcified plaques. Dualenergy CT may overcome these limitations thanks to tissue decomposition algorithms. However, this approach is still limited to research and initial results need to be validated [87].

Pericoronary adipose tissue is emerging as an imaging biomarker to identify plaque instability. Increased epicardial adipose tissue (EAT) attenuation was detected around inflamed plaques [88]. Moreover, EAT can modulate coronary artery function through paracrine and vasocrine pathways by producing cardioprotective adipokines in physiological conditions or a pro-atherogenic secretome in case of dysfunction [89]. EAT volume and its attenuation properties can be quantified by CCTA [88, 90]. In a recent study [89], an alteration of EAT attenuation was found to be associate with non-calcified and vulnerable plaques in early CAD, while in advanced CAD it was found that EAT exhibits pro-calcifying properties. The role of EAT volume and attenuation has been investigated in sparse studies and its association with CAD and outcome remains uncertain. This is mainly due to the paucity of available data, heterogeneous methodology, small sample size, and different clinical setting.

\section{CT-derived fractional flow reserve (FFR $\mathbf{R}_{\mathrm{CT}}$ ) and stress computed tomography perfusion (stress-CTP)}

FFR $_{\mathrm{CT}}$ and stress-CTP allow to integrate information about the hemodynamic significance of coronary lesions to angiographic evaluation of CAD, thus potentially avoiding additional examinations and costs. In fact, data coming from iFFR show that only $35 \%$ of anatomically obstructive lesions have positive iFFR reflecting hemodynamic significance of a stenosis. Thus, iFFR is a key parameter to guide revascularization, improving the outcome and reducing health care costs [91, 92] (Table 6).

Computational fluid dynamics allows to noninvasively estimate the FFR from CCTA [93], which has been extensively validated against iFFR in three multicentre studies [94-96]. Also an improvement in specificity and diagnostic accuracy in comparison with CCTA alone has been reported [94-96]. The high diagnostic accuracy of $\mathrm{FFR}_{\mathrm{CT}}$ is maintained also in patients with intermediate stenosis and in the presence of calcified plaques [97] or 3-vessel CAD [98].

FFR $_{\mathrm{CT}}$ modifies treatment in two-thirds of subject compared to CCTA alone [91], safely reducing unnecessary ICA [92], and predicts the outcome at 1- and 5-years [99].

Despite the advantages, $\mathrm{FFR}_{\mathrm{CT}}$ analysis is currently time consuming (2-6 h) due to software constraints and offsite analysis [100] and currently there is only one commercially available algorithm (Heart-Flow Inc., Redwood, CA). Furthermore, performance of $\mathrm{FFR}_{\mathrm{CT}}$ is strictly related to image quality. Imaging artifacts caused by low contrast, cardiac and respiratory motion, blooming due to severe calcification, and image noise due to low radiation

Table 6 Recommendations for CT-derived Fractional Flow Reserve ( $\left.\mathrm{FFR}_{\mathrm{CT}}\right)$ and stress-CT perfusion (stress-CTP)

\begin{tabular}{|c|c|c|c|}
\hline Clinical setting & Diagnostic step & $\begin{array}{l}\text { Recom- } \\
\text { menda- } \\
\text { tion }\end{array}$ & Indications \\
\hline $\mathrm{FFR}_{\mathrm{CT}}$ for evaluation of CAD & First diagnosis & $\mathrm{E}$ & $\begin{array}{l}\text { Very promising in: } \\
\text { CAD with suspected functional significance at CCTA } \\
\text { CAD with uncertain functional significance at CCTA (especially intermediate or } \\
\text { calcified lesions) } \\
\text { Evaluation of hemodynamic significance of triple vessel disease } \\
\text { However, current limited availability of validated analysis platforms hampers } \\
\text { widespread clinical application }\end{array}$ \\
\hline Stress-CTP for evaluation of CAD & First diagnosis & $\mathrm{E}$ & $\begin{array}{l}\text { Very promising in: } \\
\text { CAD with suspected functional significance at CCTA } \\
\text { CAD with uncertain functional significance at CCTA } \\
\text { Evaluation of hemodynamic significance of triple vessel disease } \\
\text { However, current lack of methodological standardization, limited validation data, } \\
\text { technological requirements, and dose concerns hamper widespread clinical } \\
\text { application }\end{array}$ \\
\hline
\end{tabular}


exposure or high body mass index hamper $\mathrm{FFR}_{\mathrm{CT}}$ performance [100].

Also, stress-CTP is capable of detecting functionally relevant stenosis, improving the diagnostic performances of CCTA, with similar performance in comparison with CCTA combined with FFR $_{\mathrm{CT}}$ [101].

Stress-CTP depicts perfusion defects as a hypo-attenuating myocardial region using either a static protocol (single scan acquired both at rest and during stress at the peak of iodine concentration in the coronaries) or a dynamic protocol in which several datasets are acquired during first pass perfusion. Dynamic stress-CTP has the advantage of providing quantitative evaluation of perfusion by estimating the myocardial blood flow [102].

Regardless of the acquisition protocol, stress-CTP requires the administration of pharmaceutical stressors and notably increases both radiation exposure and iodinated contrast agent dose.

Stress-CTP shows similar performance with respect to stress-CMR (AUC 0.91 vs 0.95 at per-patient and 0.88 vs 0.93 at per-vessel analysis) and slightly better performance than single photon emission computed tomography (AUC 0.91 vs. 0.87) [103] and has reasonably high sensitivity and specificity ( $88 \%$ and $80 \%$, respectively) in detecting flow-limiting coronary stenosis using iFFR as reference standard [104]. Importantly, the use of stress-CTP in patients at intermediate-to-high-risk of CAD was shown to improve the diagnostic performance of CCTA from 83 to $93 \%$ in a per vessel analysis [105].

However, these data need to be confirmed on larger populations. Furthermore, differently from $\mathrm{FFR}_{\mathrm{CT}}$, data on clinical utility and outcome have not been reported [106].

Acknowledgements A special thanks for the active cooperation to Luca Alessandro Cappellini, Medical Student at the School of Medicine of Vita-Salute San Raffaele University, Milan, Italy.

Open Access This article is licensed under a Creative Commons Attribution 4.0 International License, which permits use, sharing, adaptation, distribution and reproduction in any medium or format, as long as you give appropriate credit to the original author(s) and the source, provide a link to the Creative Commons licence, and indicate if changes were made. The images or other third party material in this article are included in the article's Creative Commons licence, unless indicated otherwise in a credit line to the material. If material is not included in the article's Creative Commons licence and your intended use is not permitted by statutory regulation or exceeds the permitted use, you will need to obtain permission directly from the copyright holder. To view a copy of this licence, visit http://creativecommons.org/licenses/by/4.0/.

\section{References}

1. Knuuti J, Wijns W, Achenbach S et al (2020) 2019 ESC guidelines for the diagnosis and management of chronic coronary syndromes. Eur Heart J 41:407-477

2. Collet J-P, Thiele H, Barbato E et al (2020) 2020 ESC Guidelines for the management of acute coronary syndromes in patients presenting without persistent ST-segment elevation. Eur Heart J. https://doi.org/10.1093/eurheartj/ehaa575

3. Choi EK, Il CS, Rivera JJ et al (2008) Coronary computed tomography angiography as a screening tool for the detection of occult coronary artery disease in asymptomatic individuals. J Am Coll Cardiol 52:357-365. https://doi.org/10.1016/j.jacc.2008.02. 086

4. Motoyama S, Ito H, Sarai M et al (2015) Plaque characterization by coronary computed tomography angiography and the likelihood of acute coronary events in mid-term follow-up. J Am Coll Cardiol 66:337-346. https://doi.org/10.1016/j.jacc.2015.05.069

5. Palmisano A, Vignale D, Benedetti G et al (2020) Late iodine enhancement cardiac computed tomography for detection of myocardial scars: impact of experience in the clinical practice. Radiol Medica 125:128-136. https://doi.org/10.1007/ s11547-019-01108-7

6. Lu MT, Park J, Ghemigian K et al (2016) Epicardial and paracardial adipose tissue volume and attenuation — association with high-risk coronary plaque on computed tomographic angiography in the ROMICAT II trial. Atherosclerosis. https://doi.org/10. 1016/j.atherosclerosis.2016.05.033

7. Li Y, Yu M, Dai X et al (2019) Detection of hemodynamically significant coronary stenosis: CT Myocardial Perfusion versus Machine Learning CT Fractional Flow Reserve. Radiology 293:305-314. https://doi.org/10.1148/radiol.2019190098

8. Esposito A, Gallone G, Palmisano A et al (2020) The current landscape of imaging recommendations in cardiovascular clinical guidelines: toward an imaging-guided precision medicine. Radiol Medica 125:1013-1023. https://doi.org/10.1007/ s11547-020-01286-9

9. Di Cesare E, Carbone I, Carriero A et al (2012) Clinical indications for cardiac computed tomography. From the Working Group of the Cardiac Radiology Section of the Italian Society of Medical Radiology (SIRM). Radiol Medica 117:901-938. https://doi.org/10.1007/s11547-012-0814-x

10. Bami K, Premaratne M, Lamba J et al (2017) Appropriate use criteria for cardiac computed tomography: impact on diagnostic utility. J Comput Assist Tomogr 41:746-749. https://doi.org/10. 1097/RCT.0000000000000594

11. Taylor AJ, Cerqueira M, Hodgson JMB et al (2010) ACCF/ SCCT/ACR/AHA/ASE/ASNC/NASCI/SCAI/SCMR 2010 appropriate use criteria for cardiac computed tomography. J Cardiovasc Comput Tomogr 4:407.e1-407.e33. https://doi.org/ 10.1016/j.jcct.2010.11.001

12. Martín M, Barreiro M, Cimadevilla OCF et al (2013) Appropriate criteria for the use of cardiac computed tomography angiography. Eur Heart J Cardiovasc Imaging 14:193

13. Pontone G, Di Cesare E, Castelletti S et al (2021) Appropriate use criteria for cardiovascular magnetic resonance imaging (CMR): SIC-SIRM position paper part 1 (ischemic and congenital heart diseases, cardio-oncology, cardiac masses and heart transplant). Radiol Med. https://doi.org/10.1007/s11547-020-01332-6

14. Feltes TF, Bacha E, Beekman RH et al (2011) Indications for cardiac catheterization and intervention in pediatric cardiac disease: A scientific statement from the American Heart Association. Circulation 123:2607-2652. https://doi.org/10.1161/CIR. 0b013e31821b1f10 
15. Sachdeva R, Valente AM, Armstrong AK et al (2020) ACC/ AHA/ASE/HRS/ISACHD/SCAI/SCCT/SCMR/SOPE 2020 appropriate use criteria for multimodality imaging during the follow-up care of patients with congenital heart disease. J Am Coll Cardiol. https://doi.org/10.1016/j.jacc.2019.10.002

16. Baumgartner H, De Backer J, Babu-Narayan SV et al (2020) 2020 ESC guidelines for the management of adult congenital heart disease. Eur Heart J. https://doi.org/10.1093/eurheartj/ ehaa554

17. Dyer KT, Hlavacek AM, Meinel FG et al (2014) Imaging in congenital pulmonary vein anomalies: the role of computed tomography. Pediatr Radiol 44:1158-1168

18. Kalfa DM, Serraf AE, Ly M et al (2012) Tetralogy of fallot with an abnormal coronary artery: Surgical options and prognostic factors. Eur J Cardio-thoracic Surg. https://doi.org/10.1093/ejcts/ ezs367

19. Khairy P, van Hare GF, Balaji S et al (2014) PACES/HRS expert consensus statement on the recognition and management of arrhythmias in adult congenital heart disease. Can J Cardiol 30:e1-e63. https://doi.org/10.1016/j.cjca.2014.09.002

20. Ruckdeschel ES, Quaife R, Lewkowiez L et al (2014) Preprocedural imaging in patients with transposition of the great arteries facilitates placement of cardiac resynchronization therapy leads. PACE_Pacing Clin Electrophysiol 37:546-553. https://doi.org/ 10.1111/pace. 12308

21. Morray BH, McElhinney DB, Cheatham JP et al (2013) Risk of coronary artery compression among patients referred for transcatheter pulmonary valve implantation a multicenter experience. Circ Cardiovasc Interv 6:535-542. https://doi.org/10.1161/ CIRCINTERVENTIONS.113.000202

22. Warnes CA, Williams RG, Bashore TM et al (2008) ACC/AHA 2008 guidelines for the management of adults with congenital heart disease: executive summary-a report of the American College of Cardiology/American Heart Association Task Force on practice guidelines (writing committee to develop guidelines fo. Circulation 118:2395-2451

23. Tian L, Wang L, Qin Y, Cai J (2020) Low-dose Computed Tomography (CT) for the diagnosis of congenital heart disease in children: a meta-analysis. Curr Med Imaging Former Curr Med Imaging Rev. https://doi.org/10.2174/157340561666620 0107110611

24. Agatston AS, Janowitz WR, Hildner FJ et al (1990) Quantification of coronary artery calcium using ultrafast computed tomography. J Am Coll Cardiol 15:827-832. https://doi.org/10.1016/ 0735-1097(90)90282-T

25. Winther S, Schmidt SE, Mayrhofer T et al (2020) Incorporating coronary calcification into pre-test assessment of the likelihood of coronary artery disease. J Am Coll Cardiol. https://doi.org/10. 1016/j.jacc.2020.09.585

26. Tinana A, Mintz GS, Weissman NJ (2002) Volumetric intravascular ultrasound quantification of the amount of atherosclerosis and calcium in nonstenotic arterial segments. Am J Cardiol 89:757-760. https://doi.org/10.1016/S0002-9149(01)02349-9

27. Hecht H, Blaha MJ, Berman DS et al (2017) Clinical indications for coronary artery calcium scoring in asymptomatic patients: Expert consensus statement from the Society of Cardiovascular Computed Tomography. J Cardiovasc Comput Tomogr 11:157168. https://doi.org/10.1016/j.jcct.2017.02.010

28. Khera A, Budoff MJ, O'Donnell CJ et al (2018) Astronaut cardiovascular health and risk modification (Astro-CHARM) coronary calcium atherosclerotic cardiovascular disease risk calculator. Circulation 138:1819-1827. https://doi.org/10.1161/CIRCU LATIONAHA.118.033505

29. Blaha MJ, Cainzos-Achirica M, Greenland P et al (2016) Role of coronary artery calcium score of zero and other negative risk markers for cardiovascular Disease : the Multi-Ethnic Study of
Atherosclerosis (MESA). Circulation 133:849-858. https://doi. org/10.1161/CIRCULATIONAHA.115.018524

30. Piepoli MF, Hoes AW, Agewall S et al (2016) 2016 European guidelines on cardiovascular disease prevention in clinical practice. Eur Heart J 37:2315-2381

31. Buse JB, Ginsberg HN, Bakris GL et al (2007) Primary prevention of cardiovascular diseases in people with diabetes mellitus: a scientific statement from the American Heart Association and the American Diabetes Association. Circulation 115:114-126

32. Cosentino F, Grant PJ, Aboyans V et al (2020) 2019 ESC guidelines on diabetes, pre-diabetes, and cardiovascular diseases developed in collaboration with the EASD. Eur Heart J 41:255323. https://doi.org/10.1093/eurheartj/ehz486

33. Valenti V, Hartaigh B, Cho I et al (2016) Absence of coronary artery calcium identifies asymptomatic diabetic individuals at low near-term but not long-term risk of mortality: a 15-year follow-up study of 9715 patients. Circ Cardiovasc Imaging. https:// doi.org/10.1161/CIRCIMAGING.115.003528

34. Grundy SM, Stone NJ, Bailey AL et al (2019) 2018 AHA/ACC/ AACVPR/AAPA/ABC/ACPM/ADA/AGS/APhA/ASPC/NLA/ PCNA guideline on the management of blood cholesterol: a report of the American College of Cardiology/American Heart Association Task Force on clinical practice guidelines. Circulation 139(25):e1082-e1143. https://doi.org/10.1161/CIR.00000 00000000625

35. Mahabadi AA, Möhlenkamp S, Lehmann N et al (2017) CAC score improves coronary and $\mathrm{CVv}$ risk assessment above statin indication by ESC and AHA/ACC primary prevention guidelines. JACC Cardiovasc Imaging 10:143-153. https://doi.org/10. 1016/j.jcmg.2016.03.022

36. Grundy SM, Stone NJ (2019) 2018 American Heart Association/American College of Cardiology/Multisociety Guideline on the Management of Blood Cholesterol-Secondary Prevention. JAMA Cardiol 4:589-591. https://doi.org/10.1001/jamacardio. 2019.0911

37. Cho I, Chang HJ, Hartaigh BO et al (2015) Incremental prognostic utility of coronary CT angiography for asymptomatic patients based upon extent and severity of coronary artery calcium: Results from the COronary CT Angiography EvaluatioN For Clinical Outcomes InteRnational Multicenter (CONFIRM) St. Eur Heart J. https://doi.org/10.1093/eurheartj/ehu358

38. Min JK, Labounty TM, Gomez MJ et al (2014) Incremental prognostic value of coronary computed tomographic angiography over coronary artery calcium score for risk prediction of major adverse cardiac events in asymptomatic diabetic individuals. Atherosclerosis. https://doi.org/10.1016/j.atherosclerosis.2013. 09.025

39. Muhlestein JB, Lappé DL, Lima JAC et al (2014) Effect of screening for coronary artery disease using CT angiography on mortality and cardiac events in high-risk patients with diabetes: The FACTOR-64 randomized clinical trial. JAMA—J Am Med Assoc. https://doi.org/10.1001/jama.2014.15825

40. Clerc OF, Fuchs TA, Stehli J et al (2018) Non-invasive screening for coronary artery disease in asymptomatic diabetic patients: a systematic review and meta-analysis of randomised controlled trials. Eur Heart J Cardiovasc Imaging 19:838-846

41. Celeng C, Maurovich-Horvat P, Ghoshhajra BB et al (2016) Prognostic value of coronary computed tomography angiography in patients with diabetes: a meta-analysis. Diabetes Care. https:// doi.org/10.2337/dc16-0281

42. Lehmann N, Möhlenkamp S, Mahabadi AA et al (2014) Effect of smoking and other traditional risk factors on the onset of coronary artery calcification: results of the Heinz Nixdorf recall study. Atherosclerosis. https://doi.org/10.1016/j.atherosclerosis. 2013.11.045 
43. Pelliccia A, Sharma S, Gati S et al (2020) 2020 ESC guidelines on sports cardiology and exercise in patients with cardiovascular disease. Eur Heart J. https://doi.org/10.1093/eurheartj/ehaa605

44. Gervasi SF, Palumbo L, Cammarano M et al (2019) Coronary atherosclerosis in apparently healthy master athletes discovered during pre-PARTECIPATION screening. Role of coronary CT angiography (CCTA). Int J Cardiol 282:99-107. https://doi.org/ 10.1016/j.ijcard.2018.11.099

45. Gray G, Davenport ED, Bron D et al (2019) The challenge of asymptomatic coronary artery disease in aircrew; detecting plaque before the accident. Heart 105(Suppl 1):s17-s24. https:// doi.org/10.1136/heartjnl-2018-313053

46. Kristensen SD, Knuuti J, Saraste A et al (2014) 2014 ESC/ESA guidelines on non-cardiac surgery: Cardiovascular assessment and management: the Joint Task Force on non-cardiac surgery: Cardiovascular assessment and management of the European Society of Cardiology (ESC) and the European Society of Anaesth. Eur Heart J. https://doi.org/10.1093/eurheartj/ehu282

47. Fleisher LA, Fleischmann KE, Auerbach AD et al (2014) 2014 ACC/AHA guideline on perioperative cardiovascular evaluation and management of patients undergoing noncardiac surgery: a report of the American college of cardiology/American heart association task force on practice guidelines. J Am Coll Cardiol 64:e77-e137. https://doi.org/10.1016/j.jacc.2014.07.944

48. Devereaux PJ, Sessler DI (2015) Cardiac complications in patients undergoing major noncardiac surgery. N Engl J Med. https://doi.org/10.1056/nejmra1502824

49. Koshy AN, Ha FJ, Gow PJ et al (2019) Computed tomographic coronary angiography in risk stratification prior to non-cardiac surgery: a systematic review and meta-analysis. Heart. https:// doi.org/10.1136/heartjnl-2018-314649

50. Reant P, Brunot S, Lafitte $S$ et al (2006) Predictive value of noninvasive coronary angiography with multidetector computed tomography to detect significant coronary stenosis before valve surgery. Am J Cardiol. https://doi.org/10.1016/j.amjcard.2005. 12.039

51. Meijboom WB, Mollet NR, Van Mieghem CAG et al (2006) Preoperative computed tomography coronary angiography to detect significant coronary artery disease in patients referred for cardiac valve surgery. J Am Coll Cardiol. https://doi.org/10.1016/j.jacc. 2006.06.054

52. Buffa V, De Cecco CN, Cossu L et al (2010) Preoperative coronary risk assessment with dual-source CT in patients undergoing noncoronary cardiac surgery. Radiol Med. https://doi.org/10. 1007/s11547-010-0543-y

53. Patel MR, Peterson ED, Dai D et al (2010) Low diagnostic yield of elective coronary angiography. N Engl J Med. https://doi.org/ 10.1056/nejmoa0907272

54. Douglas PS, Hoffmann U, Patel MR et al (2015) Outcomes of anatomical versus functional testing for coronary artery disease. N Engl J Med 372:1291-1300. https://doi.org/10.1056/nejmo a1415516

55. SCOT-HEART Investigators, Newby DE, Adamson PD, Berry et al (2018) Coronary CT angiography and 5-year risk of myocardial infarction. New Engl J Med 379(10):924-933. https://doi. org/10.1056/NEJMoa1805971

56. Newby D, Williams M, Hunter A et al (2015) CT coronary angiography in patients with suspected angina due to coronary heart disease (SCOT-HEART): Aan open-label, parallel-group, multicentre trial. Lancet. https://doi.org/10.1016/S0140-6736(15) 60291-4

57. Siontis GCM, Mavridis D, Greenwood JP et al (2018) Outcomes of non-invasive diagnostic modalities for the detection of coronary artery disease: network meta-analysis of diagnostic randomised controlled trials. BMJ. https://doi.org/10.1136/ bmj.k504
58. Collet C, Onuma Y, Andreini D et al (2018) Coronary computed tomography angiography for heart team decision-making in multivessel coronary artery disease. Eur Heart J. https://doi. org/10.1093/eurheartj/ehy581

59. 2019 surveillance of chest pain of recent onset: assessment and diagnosis (NICE guideline CG95) (2019) National Institute for Health and Care Excellence, UK

60. Pontone G (2016) Anatomy and physiology in ischaemic heart disease: a second honeymoon? Eur Heart J 37(15):1228-1231. https://doi.org/10.1093/eurheartj/ehv748

61. Park HB, Heo R, Hartaigh Ó, B, et al (2015) Atherosclerotic plaque characteristics by $\mathrm{CT}$ angiography identify coronary lesions that cause ischemia: a direct comparison to fractional flow reserve. JACC Cardiovasc Imaging. https://doi.org/10. 1016/j.jcmg.2014.11.002

62. Arbab-Zadeh A, Miller JM, Rochitte CE et al (2012) Diagnostic accuracy of computed tomography coronary angiography according to pre-test probability of coronary artery disease and severity of coronary arterial calcification: the CORE-64 (Coronary Artery Evaluation Using 64-Row Multidetector Computed Tomog. J Am Coll Cardiol. https://doi.org/10.1016/j.jacc.2011. 06.079

63. Cademartiri F, Maffei E, Palumbo A et al (2007) Diagnostic accuracy of 64-slice computed tomography coronary angiography in patients with low-to-intermediate risk. Radiol Med. https://doi.org/10.1007/s11547-007-0198-5

64. Neglia D, Rovai D, Caselli C et al (2015) Detection of significant coronary artery disease by noninvasive anatomical and functional imaging. Circ Cardiovasc Imaging. https://doi.org/10.1161/ CIRCIMAGING.114.002179

65. Mollet NR, Cademartiri F, Nieman K et al (2004) Multislice spiral computed tomography coronary angiography in patients with stable angina pectoris. J Am Coll Cardiol. https://doi.org/ 10.1016/j.jacc.2004.03.032

66. Budoff MJ, Dowe D, Jollis JG et al (2008) Diagnostic performance of 64-multidetector row coronary computed tomographic angiography for evaluation of coronary artery stenosis in individuals without known coronary artery disease. Results from the prospective multicenter ACCURACY (Assessment by Coro. J Am Coll Cardiol 52:1724-1732. https://doi.org/10.1016/j.jacc. 2008.07.031

67. Dewey M, Dübel HP, Schink T et al (2007) Head-to-head comparison of multislice computed tomography and exercise electrocardiography for diagnosis of coronary artery disease. Eur Heart J. https://doi.org/10.1093/eurheartj/ehl148

68. Maffei E, Seitun S, Martini C et al (2010) CT coronary angiography and exercise ECG in a population with chest pain and lowto-intermediate pre-test likelihood of coronary artery disease. Heart. https://doi.org/10.1136/hrt.2009.191361

69. Pontone G, Andreini D, Bertella E et al (2016) Impact of an intra-cycle motion correction algorithm on overall evaluability and diagnostic accuracy of computed tomography coronary angiography. Eur Radiol. https://doi.org/10.1007/s00330-015-3793-1

70. Dewey M, Vavere AL, Arbab-Zadeh A et al (2010) Patient characteristics as predictors of image quality and diagnostic accuracy of MDCT compared with conventional coronary angiography for detecting coronary artery stenoses: CORE-64 multicenter international trial. Am J Roentgenol. https://doi.org/10.2214/AJR.09. 2833

71. Pontone G, Bertella E, Mushtaq S et al (2014) Coronary artery disease: diagnostic accuracy of CT coronary angiography-a comparison of high and standard spatial resolution scanning. Radiology. https://doi.org/10.1148/radiol.13130909

72. Maffei E, Martini C, Rossi A et al (2012) Diagnostic accuracy of second-generation dual-source computed tomography coronary angiography with iterative reconstructions: a 
real-world experience. Radiol Med. https://doi.org/10.1007/ s11547-011-0754-x

73. Kannel WB, D'Agostino RB, Sullivan L, Wilson PWF (2004) Concept and usefulness of cardiovascular risk profiles. Am Heart J. https://doi.org/10.1016/j.ahj.2003.10.022

74. Lee UW, Ahn S, Shin YS et al (2020) Comparison of the CAD consortium and updated Diamond-Forrester scores for predicting obstructive coronary artery disease. Am J Emerg Med. https:// doi.org/10.1016/j.ajem.2020.02.056

75. Pundziute G, Schuijf JD, Jukema JW et al (2008) Head-to-head comparison of coronary plaque evaluation between multislice computed tomography and intravascular ultrasound radiofrequency data analysis. JACC Cardiovasc Interv. https://doi.org/ 10.1016/j.jcin.2008.01.007

76. Lee SE, Chang HJ, Sung JM et al (2018) Effects of statins on coronary atherosclerotic plaques: the PARADIGM study. JACC Cardiovasc Imaging 11:1475-1484. https://doi.org/10.1016/j. jcmg.2018.04.015

77. Min JK, Berman DS, Dunning A et al (2012) All-cause mortality benefit of coronary revascularization vs. medical therapy in patients without known coronary artery disease undergoing coronary computed tomographic angiography: results from $\mathrm{CON}$ FIRM (COronary CT Angiography EvaluatioN for Clinical Out. Eur Heart J 33:3088-3097. https://doi.org/10.1093/eurheartj/ ehs315

78. Maddox TM, Stanislawski MA, Grunwald GK et al (2014) Nonobstructive coronary artery disease and risk of myocardial infarction. JAMA 312:1754-1763. https://doi.org/10.1001/jama.2014. 14681

79. Ferraro RA, van Rosendael AR, Lu Y et al (2020) Non-obstructive high-risk plaques increase the risk of future culprit lesions comparable to obstructive plaques without high-risk features: the iconic study. Eur Heart J Cardiovasc Imaging 21:973-980. https://doi.org/10.1093/ehjci/jeaa048

80. Hoffmann U, Ferencik M, Udelson JE et al (2017) Prognostic value of noninvasive cardiovascular testing in patients with stable chest pain: insights from the PROMISE Trial (Prospective Multicenter Imaging Study for Evaluation of Chest Pain). Circulation 135:2320-2332. https://doi.org/10.1161/CIRCULATIONAHA. 116.024360

81. Puchner SB, Liu T, Mayrhofer T et al (2014) High-risk plaque detected on coronary CT angiography predicts acute coronary syndromes independent of significant stenosis in acute chest pain: results from the ROMICAT-II trial. J Am Coll Cardiol. https://doi.org/10.1016/j.jacc.2014.05.039

82. Motoyama S, Sarai M, Harigaya H et al (2009) Computed tomographic angiography characteristics of atherosclerotic plaques subsequently resulting in acute coronary syndrome. J Am Coll Cardiol. https://doi.org/10.1016/j.jacc.2009.02.068

83. Van Werkhoven JM, Schuijf JD, Gaemperli O et al (2009) Incremental prognostic value of multi-slice computed tomography coronary angiography over coronary artery calcium scoring in patients with suspected coronary artery disease. Eur Heart J 30:2622-2629. https://doi.org/10.1093/eurheartj/ehp272

84. Lee SE, Sung JM, Andreini D et al (2020) Differences in progression to obstructive lesions per high-risk plaque features and plaque volumes With CCTA. JACC Cardiovasc Imaging 13:1409-1417. https://doi.org/10.1016/j.jcmg.2019.09.011

85. Mushtaq S, De Araujo GP, Garcia-Garcia HM et al (2015) Longterm prognostic effect of coronary atherosclerotic burden validation of the computed tomography-leaman score. Circ Cardiovasc Imaging. https://doi.org/10.1161/CIRCIMAGING.114.002332

86. Cury RC, Abbara S, Achenbach S et al (2016) CAD-RADSTM Coronary Artery Disease-Reporting and Data System. An expert consensus document of the Society of Cardiovascular Computed Tomography (SCCT), the American College of
Radiology (ACR) and the North American Society for Cardiovascular Imaging (NASCI). Endorsed by the American College of Cardiology. J Cardiovasc Comput Tomogr 10:269-281. https://doi.org/10.1016/j.jcct.2016.04.005

87. Danad I, Fayad ZA, Willemink MJ, Min JK (2015) New applications of cardiac computed tomography: dual-energy, spectral, and molecular CT imaging. JACC Cardiovasc Imaging 8:710-723

88. Antonopoulos AS, Sanna F, Sabharwal N et al (2017) Detecting human coronary inflammation by imaging perivascular fat. Sci Transl Med. https://doi.org/10.1126/scitranslmed.aal2658

89. Mancio J, Barros AS, Conceicao G et al (2020) Epicardial adipose tissue volume and annexin A2/fetuin-A signalling are linked to coronary calcification in advanced coronary artery disease: computed tomography and proteomic biomarkers from the EPICHEART study. Atherosclerosis 292:75-83. https://doi.org/10. 1016/j.atherosclerosis.2019.11.015

90. Mahabadi AA, Balcer B, Dykun I et al (2017) Cardiac computed tomography-derived epicardial fat volume and attenuation independently distinguish patients with and without myocardial infarction. PLoS ONE. https://doi.org/10.1371/journal.pone. 0183514

91. Fairbairn TA, Nieman K, Akasaka T et al (2018) Real-world clinical utility and impact on clinical decision-making of coronary computed tomography angiography-derived fractional flow reserve: lessons from the ADVANCE Registry. Eur Heart J. https://doi.org/10.1093/eurheartj/ehy530

92. Douglas PS, De Bruyne B, Pontone G et al (2016) 1-Year outcomes of FFRCT-guided care in patients with suspected coronary disease: the PLATFORM study. J Am Coll Cardiol. https://doi. org/10.1016/j.jacc.2016.05.057

93. Pontone G, Muscogiuri G, Andreini D et al (2016) The new frontier of cardiac computed tomography angiography: fractional flow reserve and stress myocardial perfusion. Curr Treat Opt Cardiovasc Med 18(12):74. https://doi.org/10.1007/ s11936-016-0493-3

94. Min JK, Leipsic J, Pencina MJ et al (2012) Diagnostic accuracy of fractional flow reserve from anatomic CT angiography. JAMA - J Am Med Assoc. https://doi.org/10.1001/2012.jama.11274

95. Nørgaard BL, Leipsic J, Gaur S et al (2014) Diagnostic performance of noninvasive fractional flow reserve derived from coronary computed tomography angiography in suspected coronary artery disease: the NXT trial (Analysis of Coronary Blood Flow Using CT Angiography: Next Steps). J Am Coll Cardiol. https:// doi.org/10.1016/j.jacc.2013.11.043

96. Koo BK, Erglis A, Doh JH et al (2011) Diagnosis of ischemiacausing coronary stenoses by noninvasive fractional flow reserve computed from coronary computed tomographic angiograms: Results from the prospective multicenter DISCOVER-FLOW (Diagnosis of Ischemia-Causing Stenoses Obtained Via Noni. J Am Coll Cardiol. https://doi.org/10.1016/j.jacc.2011.06.066

97. Nørgaard BL, Gaur S, Leipsic J et al (2015) Influence of coronary calcification on the diagnostic performance of CT angiography derived FFR in coronary artery disease a substudy of the NXT trial. JACC Cardiovasc Imaging. https://doi.org/10.1016/j.jcmg. 2015.06.003

98. Collet C, Miyazaki Y, Ryan N et al (2018) Fractional flow reserve derived from computed tomographic angiography in patients with multivessel CAD. J Am Coll Cardiol. https://doi.org/10. 1016/j.jacc.2018.02.053

99. Fournier S, Collet C, Xaplanteris P et al (2020) Global fractional flow reserve value predicts 5 -year outcomes in patients with coronary atherosclerosis but without ischemia. J Am Heart Assoc 9:e017729. https://doi.org/10.1161/JAHA.120.017729

100. Nørgaard BL, Leipsic J, Koo BK et al (2016) Coronary computed tomography angiography derived fractional flow reserve and plaque stress. Curr Cardiovasc Imaging Rep 9:1-12 
101. Pontone G, Baggiano A, Andreini D et al (2019) stress computed tomography perfusion versus fractional flow reserve ct derived in suspected coronary artery disease: the PERFECTION study. JACC Cardiovasc Imaging. https://doi.org/10.1016/j.jcmg.2018. 08.023

102. Varga-Szemes A, Meinel FG, De Cecco CN, Fuller SR, Bayer RR 2nd, Schoepf UJ (2015) CT myocardial perfusion imaging. Am J Roentgenol 204(3):487-497. https://doi.org/10.2214/AJR. 14.13546

103. Yang Z, Zheng H, Zhou T et al (2015) Diagnostic performance of myocardial perfusion imaging with SPECT, CT and MR compared to fractional flow reserve as reference standard. Int J Cardiol 190:103-105. https://doi.org/10.1016/j.ijcard.2015.04.091

104. Meinel FG, Ebersberger U, Schoepf UJ et al (2014) Global quantification of left ventricular myocardial perfusion at dynamic CT: feasibility in a multicenter patient population. Am J Roentgenol. https://doi.org/10.2214/AJR.13.12328
105. Pontone G, Baggiano A, Andreini D et al (2018) Diagnostic accuracy of simultaneous evaluation of coronary arteries and myocardial perfusion with single stress cardiac computed tomography acquisition compared to invasive coronary angiography plus invasive fractional flow reserve. Int J Cardiol. https://doi. org/10.1016/j.ijcard.2018.09.065

106. Coenen A, Rossi A, Lubbers MM et al (2017) Integrating CT myocardial perfusion and CT-FFR in the work-up of coronary artery disease. JACC Cardiovasc Imaging. https://doi.org/10. 1016/j.jcmg.2016.09.028

Publisher's Note Springer Nature remains neutral with regard to jurisdictional claims in published maps and institutional affiliations.

\section{Authors and Affiliations}

\section{Antonio Esposito ${ }^{1,2}$ (D) Marco Francone ${ }^{3,4} \cdot$ Daniele Andreini $^{5,6} \cdot$ Vitaliano Buffa $^{7} \cdot$ Filippo Cademartiri $^{8}$. lacopo Carbone ${ }^{9}$. Alberto Clemente ${ }^{10}$. Andrea Igoren Guaricci ${ }^{11}$. Marco Guglielmo ${ }^{5}$. Ciro Indolfi ${ }^{12}$. Ludovico La Grutta ${ }^{13}$. Guido Ligabue ${ }^{14,15}$. Carlo Liguori ${ }^{16}$. Giuseppe Mercuro ${ }^{17}$. Saima Mushtaq ${ }^{5}$. Danilo Neglia ${ }^{18}$. Anna Palmisano ${ }^{1,2} \cdot$ Roberto Sciagrà $^{19} \cdot$ Sara Seitun $^{20} \cdot$ Davide Vignale $^{1,2}$. Gianluca Pontone ${ }^{5}$. Nazario Carrabba ${ }^{21}$}

1 Clinical and Experimental Radiology Unit, Experimental Imaging Center, IRCCS Ospedale San Raffaele, Via Olgettina 60, 20132 Milan, Italy

2 Vita-Salute San Raffaele University, Milan, Italy

3 Department of Biomedical Sciences, Humanitas University, Milan, Italy

4 Humanitas Research Hospital IRCCS, Rozzano, Milan, Italy

5 Centro Cardiologico Monzino IRCCS, Milan, Italy

6 Department of Clinical Sciences and Community Health, University of Milan, Milan, Italy

7 Department of Radiology, Azienda Ospedaliera San Camillo Forlanini, Rome, Italy

8 SDN IRCCS, Naples, Italy

9 Department of Radiological, Oncological and Pathological Sciences, "Sapienza" University of Rome, Rome, Italy

10 Fondazione Toscana G. Monasterio, Massa and Pisa, Italy

11 Cardiothoracic Department, University Cardiology Unit, Policlinic University Hospital, Bari, Italy

12 Department of Medical and Surgical Sciences, Magna Grecia University, Catanzaro, Italy
13 Department of Health Promotion, Mother and Child Care, Internal Medicine and Medical Specialties-ProMISE, University of Palermo, AOUP P. Giaccone, Palermo, Italy

14 Department of Medical and Surgical Sciences, Modena and Reggio Emilia University, Modena, Italy

15 Radiology Department, AOU of Modena, Modena, Italy

16 Radiology Unit, Ospedale del Mare- A.S.LNa1-Centro, Naples, Italy

17 Department of Medical Sciences and Public Health, University of Cagliari, Cagliari, Italy

18 Cardiovascular Department, CNR (National Council of Research)/Tuscany Region 'Gabriele Monasterio' Foundation (FTGM), Pisa, Italy

19 Nuclear Medicine Unit, Department of Experimental and Clinical Biomedical Sciences "Mario Serio", University of Florence, Florence, Italy

20 Radiology Department, Ospedale Policlinico San Martino, IRCCS Per L'Oncologia E Le Neuroscienze, Genoa, Italy

21 Cardiothoracovascular Department, Azienda Ospedaliero Universitaria Careggi, Florence, Italy 